\title{
California Climate Change, Hydrologic Response, and Flood Forecasting
}

\author{
Norman L. Miller \\ Earth Sciences Division, Berkeley National Laboratory, Berkeley, California, USA
}

\section{Introduction}

California has ecological, cultural, and geographical diversity with 10 natural bioregions (Northern Coastal, Central Coastal, Southern Coastal, Great Central Valley, Cascade Mountains, Sierra Nevada Mountains, East of Sierra Nevada, Mojave Desert, and Sonoran Desert), and several urban centers. Its population exceeds 33 million, with the largest concentrations in the Los Angeles Basin, San Francisco Bay Area, and within the Central Valley. It has an area of approximately $420,000 \mathrm{~km}^{2}$, with over $2000 \mathrm{~km}$ of coastline, and $3000 \mathrm{~km}^{2}$ of lakes, bays, and deltas. Areas within the San Francisco Bay Delta are below sea level and have levees, retaining walls, and drainage ponds, which along with the California coastal areas, are vulnerable to stormgenerated tidal surges, flooding, erosion, and loss of property.

California has experienced long dry and unusually wet periods. Oxygen-18 isotope analyses (Ingram et al. 1996) of San Francisco Bay sediments dating back to about 1200 A.D have indicated changes in salinity, which are indicators of fresh water inflow to the San Francisco Bay. Periods of very high fresh water inflow to the San Francisco Bay (i.e. increased precipitation and low salinity) alternate with periods of low fresh water inflow (i.e. decreased precipitation and high salinity). During the 1500 s, there appears to have been a drought that lasted more than 50 years (Fig. 1). Since the beginning of the 1900s, California has been wetter than average, and large engineering projects for water storage and conveyance of Sierra Nevada snowmelt runoff have contributed to the economic growth of California. The sustainability of this region is closely aligned with the availability of fresh water, the storage of this water during dry periods, and the reduction or adaptation to major floods that can potentially damage vital infrastructure.

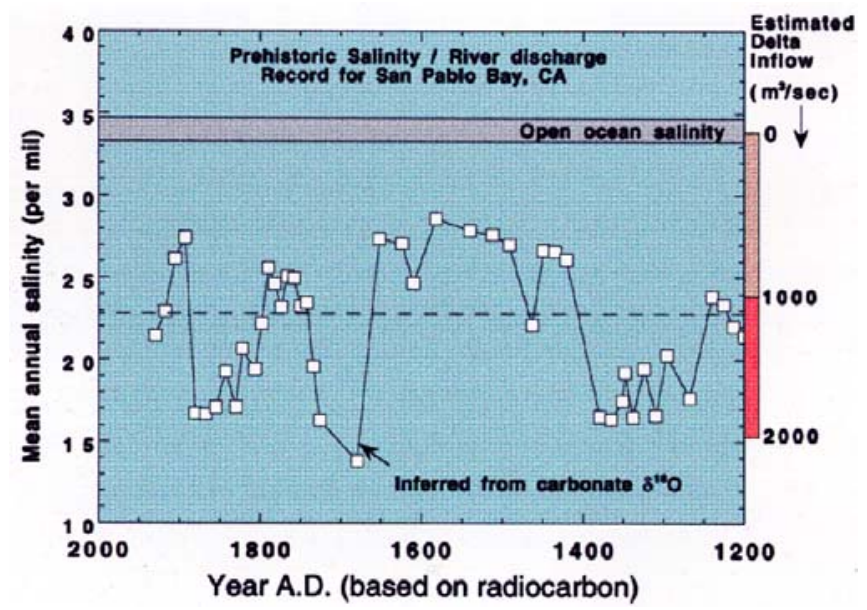

Fig. 1. Oxygen-18 isotope dating of sediments indicates pre-historic periods of high salinity and low inflow (low precipitation), and periods of low salinity and high inflow (high precipitation). The red side-bar represents the estimated fresh water inflow corresponding to the salinity concentration (Ingram et al. 1996). 
California has a Mediterranean climate and receives precipitation from November to April, with May through October being dry month. Precipitation is from the Pacific Ocean and involves large-scale atmospheric circulations that are influenced by Pacific Ocean sea surface temperatures (SSTs). The SST patterns affect low frequency climate oscillations that impact precipitation rates in regions around the world through natural teleconnected climate variations. For California, the two most significant are the El Nino Southern Oscillation (ENSO) and the Pacific multi-Decadal Oscillation (PDO). ENSO has a 3-5 year cycle, responds to changes in the western equatorial Pacific Ocean SSTs, and is termed El Nino for its positive phase, and La Nina for its negative phase. The PDO responds to SST patterns in the northern, equatorial, and southern Pacific Ocean, has an approximately 30 year cycle, and is weaker than ENSO. Major El Nino phase events are shown in Fig. 2 and the global precipitation impacts due to the very large 1982-1983 El Nino are shown Fig. 3.

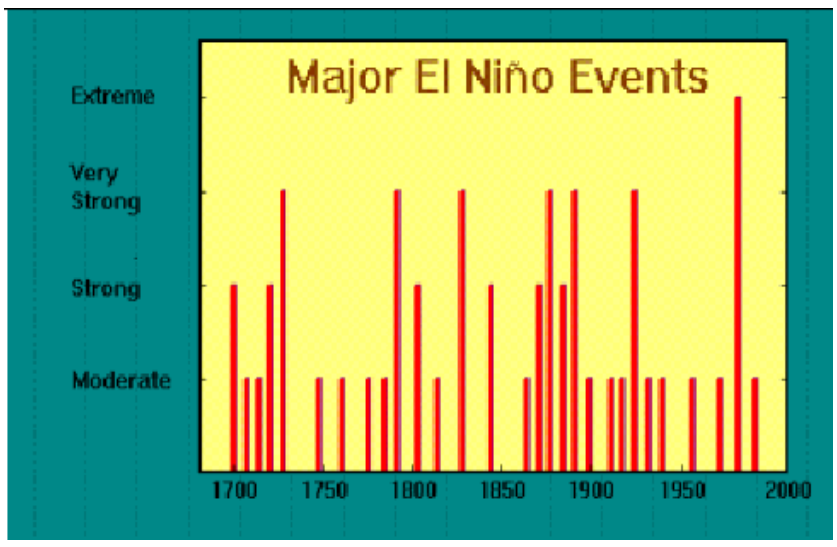

Fig. 2. Major E1 Nino events since 1700. The 1982-1983 event was the largest on record.

Worldwide Droughts, 1982-83

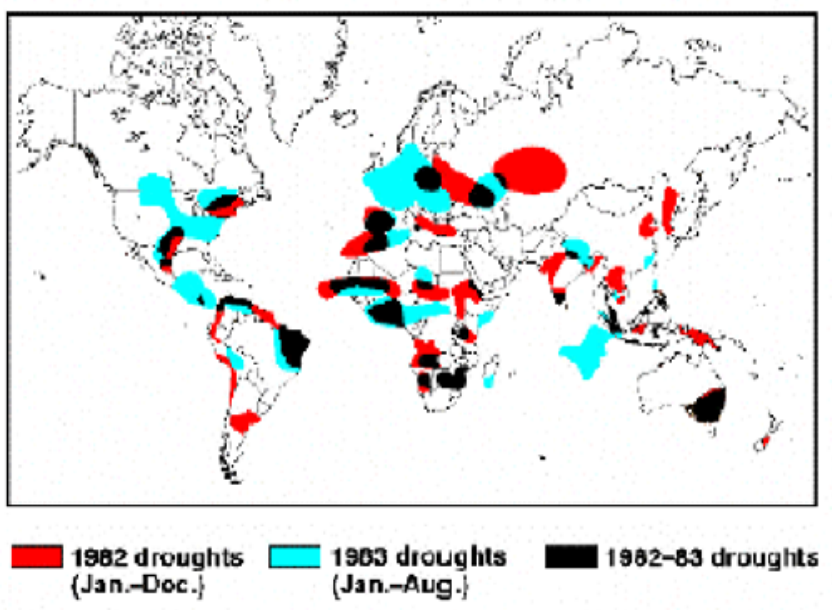

Fig. 3. During the 1982-1983 El Nino, teleconnected patterns caused global impacts, most importantly droughts and floods. 
During the last 50 years, there has been an observed global warming of the lower atmosphere at rates greater than direct observations over the previous 150 years and greater than proxy studies that date back 1000 years (Fig. 4). As much as 30 percent of this recent warming can be attributed to natural climate variability, including ENSO, PDO, and other phenomena. However, studies have provided strong evidence of climate change due to the emission of carbon dioxide $\left(\mathrm{CO}_{2}\right)$ and other anthropogenic green house gas (GHG) emissions. Since the late 1950s, observations have indicated that the global temperature of the lower atmosphere (troposphere) has increased on average $0.1{ }^{\circ} \mathrm{C}$ per decade, with the 1990 s the warmest decade of the century. Global input of $\mathrm{CO}_{2}$ to the atmosphere from fossil fuel combustion has exponentially increased since the beginning of the industrial revolution (i.e. 1860) at about 4\% per year. Atmospheric $\mathrm{CO}_{2}$ measurements (Keeling et al. 1989) from Mauna Loa, Hawaii beginning in the late 1950s show increasing atmospheric $\mathrm{CO}_{2}$ concentrations from near $280 \mathrm{ppm}$ during the late $1950 \mathrm{~s}$ to concentrations greater than $360 \mathrm{ppm}$ in the 1990s (Fig. 5). Ice core measurements from Vostok, Antarctica indicate that the atmospheric $\mathrm{CO}_{2}$ concentration was less than $280 \mathrm{ppm}$ for the last 100,000 years (Barnola et al. 1987). It is well understood that $\mathrm{CO}_{2}$ and other anthropogenic emissions (e.g. methane, nitrous oxide, halocarbons) act as heat trapping GHGs, that radiatively force the global climate and increase tropospheric temperature. This increase in atmospheric $\mathrm{CO}_{2}$ concentration and temperature appears to be causing a range of impacts, some of which may have adverse consequences.

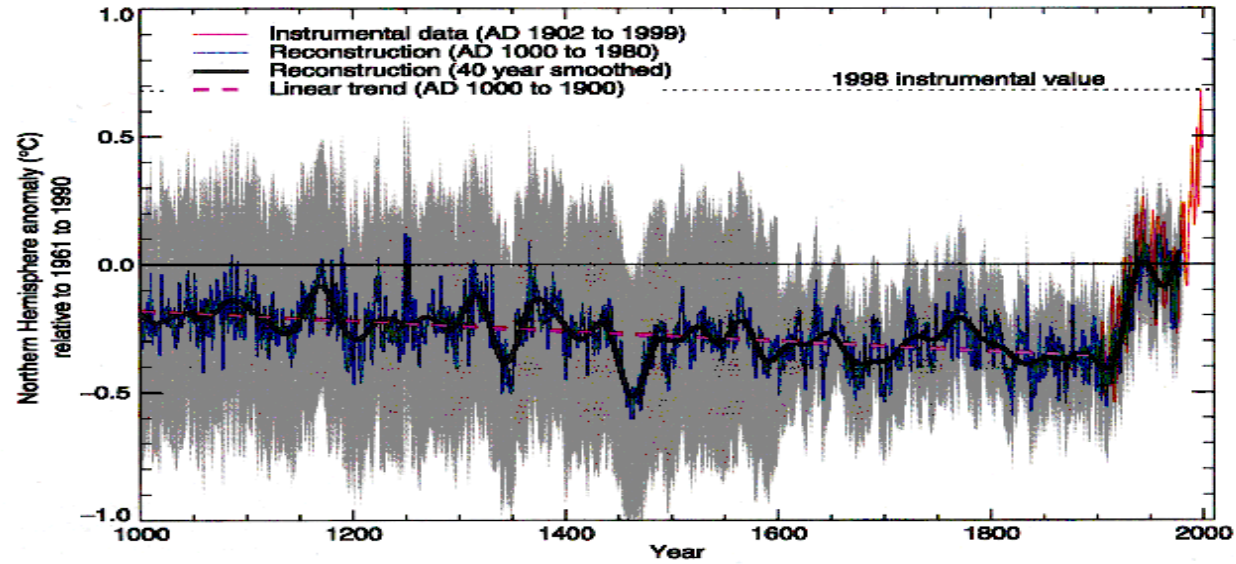

Fig. 4. The observed temperature record from 1860 to present is shown in red, the reconstructed paleo-temperature record for the period 1000 to $1980 \mathrm{AD}$ is shown in blue, with a 40 year smoothed version of the paleo-record in black. The linear trend (red dashed) decreases until about 1860, when historically high rates of temperature increase are observed.

In response to this warming and the potential impacts, the Intergovernmental Panel on Climate Change (IPCC) was established in 1988 and the First Assessment Report released in 1990 provided a discussion of these concerns and provided global and regional climate model projections, framed with uncertainties (IPCC 1990). In 1995, the IPCC Second Assessment Report (IPCC 1995) stated that the balance of evidence suggested a discernable human influence on global climate. The Third Assessment Report (IPCC 2001) has stated that there is new and stronger evidence that most of the warming observed over the last 50 years is attributable to human activities, and warming will continue throughout the 21 st century. 
The IPCC (2001) ranked the confidence limits of major impacts to water resources due to observed and projected climate change as very high (0.95-1.00), high (0.67-0.95), medium (0.33$0.67)$, low (0.05-0.33), and very low (0.00-0.05). There is high confidence that the timing and amount of runoff is changing, and very high confidence that watersheds with substantial snowpack will experience major changes as temperature continues to rise. The impacts of this trend are a decrease in available water resources in California, primarily during the summer months, and a potential increase in wintertime floods. There is high confidence that California's Sierra Nevada will experience a continued trend of decreased snow accumulation and earlier snowmelt (e.g. Lettenmaier and Gan 1990; Jeton et al. 1996; Miller et al. 1999; Wilby and Dettinger 2000; Knowles and Cayan 2002; Miller et al. 2003).

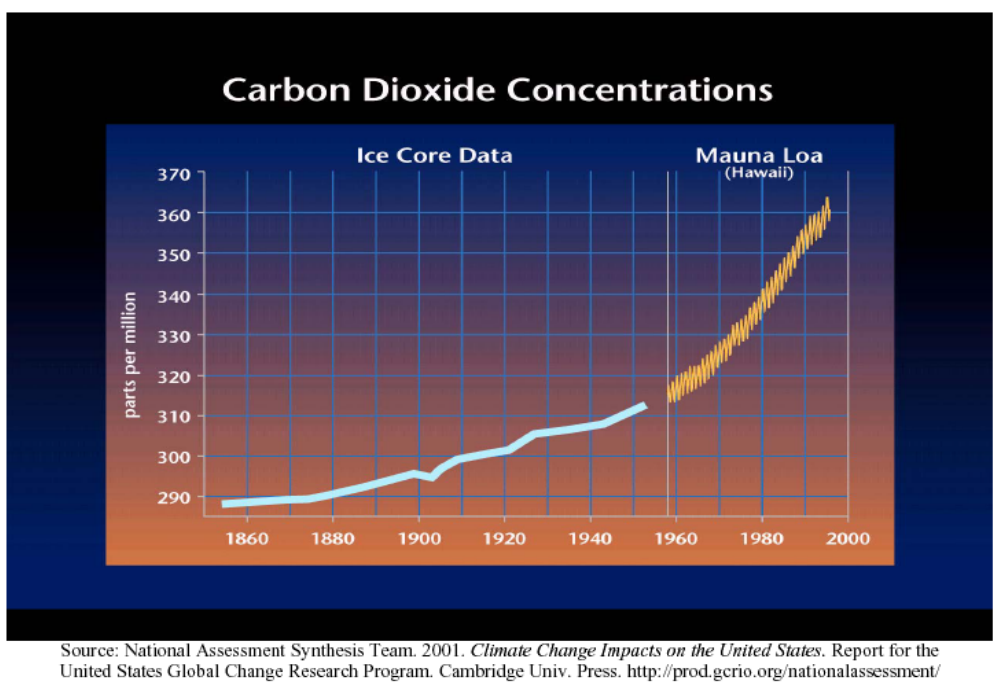

Fig. 5. The observed $\mathrm{CO}_{2}$ concentration at Mauna Loa for 1959 to 1995 correlates well with the observed temperature increase shown in Fig. 4.

Precipitation change is very location-dependent and at present there is low confidence on changes in frequency, intensity, and persistence. There is medium confidence that there will be increased flooding in regions that experience large increases in precipitation. The IPCC (2001) suggests that flooding may become a major problem, raising concerns about property damage and levee failure. There is high confidence that increased temperature will cause sea level rise through thermal expansion and increased freshwater input (snow melt runoff, glacier calving). There is high confidence that this will impact groundwater aquifers, surface freshwater systems, and urban areas in The Netherlands, the San Francisco Bay-Delta, and other low lying regions. Sea level rise will cause an increase in erosion and storm surges increasing the extent of damage to coastal areas, bays, levees, and water conveyance structures.

\section{Modeling Climate Change and Hydrology}

Atmospheric-Ocean General Circulation Models (AOGCMs) represent a coarse spatial approximation of the global climate system and its response to changes in atmospheric composition. Climate projections are initialized by output from carbon cycle model projections indicating future $\mathrm{CO}_{2}$ concentrations of 250 to $970 \mathrm{ppm}$ representing GHG concentrations of 90 to $250 \%$ of the pre-industrial $280 \mathrm{ppm}$. This range brackets projected Business as Usual scenarios and significant GHG reduction scenarios. Aerosols such as sulphates and black carbon reflect solar radiation in the troposphere causing a cooling effect. Naturally occurring aerosols such as 
volcanic emissions also play into this uncertainty. Since the $1990 \mathrm{~s}$, these aerosols have begun to be added as part of emission scenarios models along with $\mathrm{CO}_{2}$ concentrations.

The IPCC AOGCM projections of $21^{\text {st }}$ century climate, with a transient increase in greenhouse gas emissions, suggest that the global mean near-surface air temperature will increase by 1.4 to $5.8{ }^{\circ} \mathrm{C}$, with a $95 \%$ probability interval of 1.7 to $4.9^{\circ} \mathrm{C}$ by 2100 (Wigley and Raper 2001). The potential for impacts on water resources due to global warming requires a downscaled analysis of local watershed hydrology. To quantify the uncertainty in streamflow, upper and lower temperature and precipitation projections and specified incremental temperature and precipitation changes are used as input forcing to hydrologic models.

Miller et al. (2003) performed an analysis of California hydrologic response to $21^{\text {st }}$ century future climate temperature and precipitation based on two AOGCM projections representing the spread of possible outcomes. The models used are the Hadley Centre HadCM2, a warm and wet projection, and the National Center for Atmospheric Research PCM, a cool and dry projection, relative to the mean of the IPCC AOGCM projections (Fig. 6). Climate change perturbations of the projected watershed mean-area temperature and precipitation were derived from the temperature difference and precipitation ratio between the projected climatology and the simulated present day baseline climate (1961 to 1990).

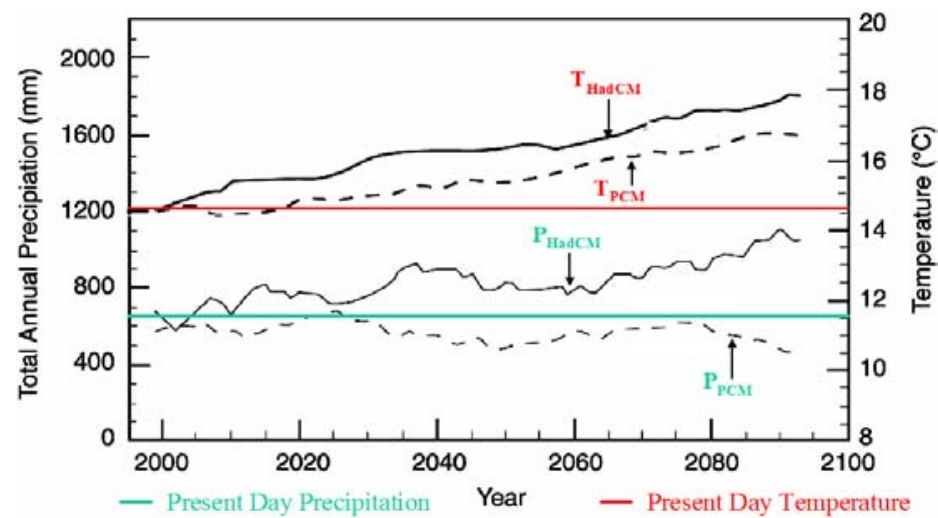

Fig. 6. The California area-averaged temperature for HadCM2 and PCM show an increase from present day (red) of approximately $4.5^{\circ} \mathrm{C}$ and $2.1^{\circ} \mathrm{C}$, respectively, by 2100 . While the HadCM2 shows a precipitation increase of approximately $1.9 \%$ and the PCM decreases by $0.85 \%$ from the present day precipitation (green).

\section{Hydrologic Response to Climate Change}

The hydrologic response was investigated using the U.S. National Weather Service Sacramento Soil Moisture Accounting Model and Anderson Snow Model (Burnash et al. 1973) for a set of representative study watersheds (Smith River, Sacramento River, Feather River, American River, Merced River, Kings River) forced by precipitation and temperature perturbations. These watersheds (Fig. 7) were selected to evaluate the shifts in timing and magnitude for runoff in the Cascade Mountains, Sierra Nevada Mountains, and Northern Coastal mountains, as $80 \%$ of California's fresh water comes from these regions. Comparisons were made between present-day (1961-1990) hydrology and the hydrologic response to the relatively warm, wet projection and the cool, dry projection. Changes in the rain-to-snow ratio, streamflow, and the range in daily high streamflow return periods (i.e. change in probability of floods) were determined. The 
following discussion is focused on a subset of these watersheds; the Sacramento, the American, and the Merced.

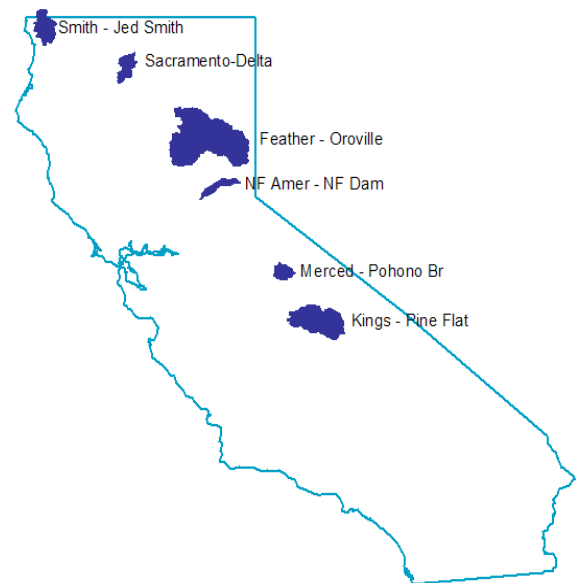

Fig. 7. California study watersheds are the Smith River, Sacramento River, Feather River, North Fork American River, Merced River, and the Kings River. These were chosen to examine the runoff response for major California fresh water sources via similarity. The discussion focuses primarily on the Sacramento, American, and Merced Rivers.

The resulting HadCM2-forced peak flow increases for the Sacramento, American and Merced during 2010 to 2039. During 2050 to 2079 and the 2080 to 2099, the peak flow magnitude continues to increase, with the greatest increase at the American River (Fig. 8, left column).
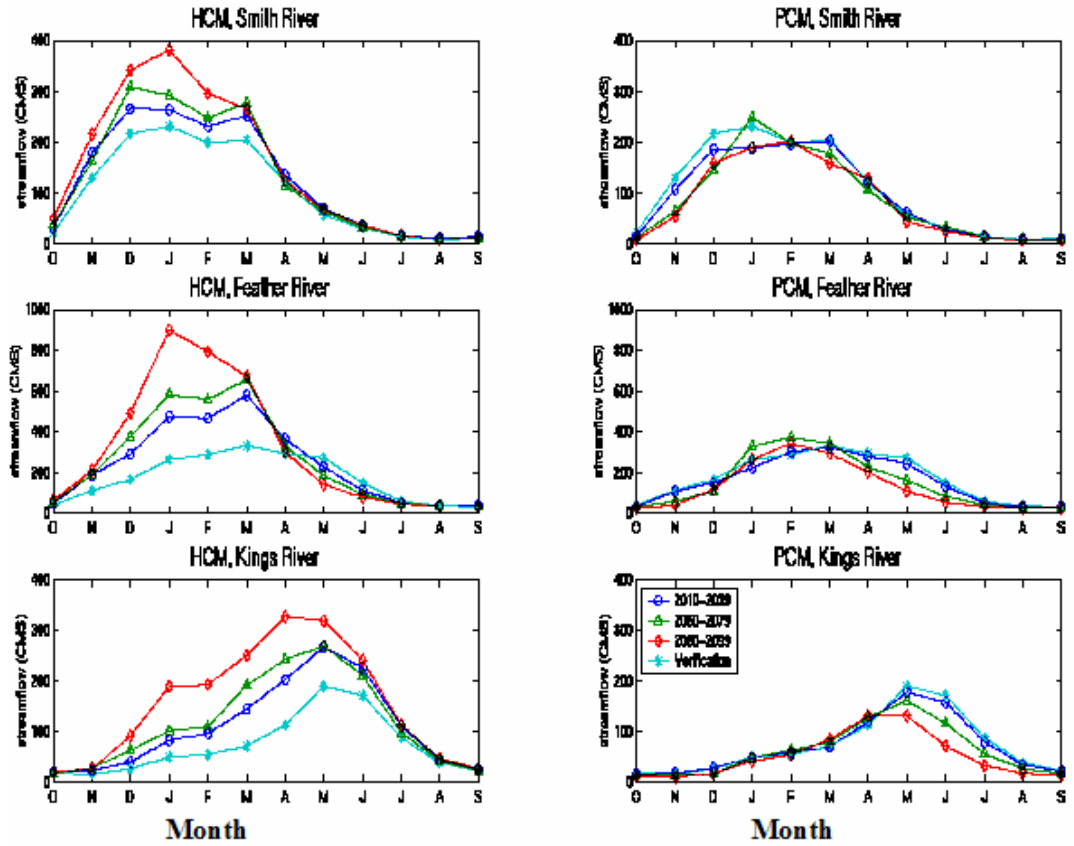

Fig. 8. Streamflow monthly climatologies based on HadCM2 (left column) and PCM (right column), for the Sacramento River, American River, and Merced River, for present day (light blue, validation), 2010-2039 (dark blue, circle), 2050-2079 (green, triangle), and 2079-2099 (red, diamond). 
The peak flow timing during the 2080 to 2099 period for the American is a month earlier, occurring in February, while the Sacramento (rainfall-dominant watershed) timing remains relatively unchanged. The higher elevation Merced peak flow occurs one month later than the historical, and it also shows a secondary peak flow during December. This secondary high flow is due to increased early season snowmelt and higher snowline due to the increased temperature. The relatively cool, dry PCM-forced streamflow (right column figures) slightly decreases in total volume and significantly decreases during the March to July melt season. Peak flow remains close to the historical for the Sacramento and American for all projected periods, but the Merced shows an increase during the 2010 to 2039 period, and decreases during 2050 to 2079 and 2080 to 2099. For these projections, the American shows an earlier peak flow of one month, while the peak flow for the other two watersheds shown here remains consistent with the historical peak flow timing. Under the scenarios studied, peak streamflow in the snowmelt runoff watersheds occurs earlier and with increased magnitude and decreased summer season flow.

From a water resources perspective, the most significant finding common to both the HadCM2 and the PCM is a 50 percent decrease in total snow for California by 2100 (Fig.9). The one exception is the very high elevation Merced, which is sufficiently cold that it remains below freezing during most of the snow accumulation season. Such reductions in available fresh water will impact agricultural and urban water use. April $1^{\text {st }}$ is the time when the California Department of Water Resources determines the amount of water available for the dry season.
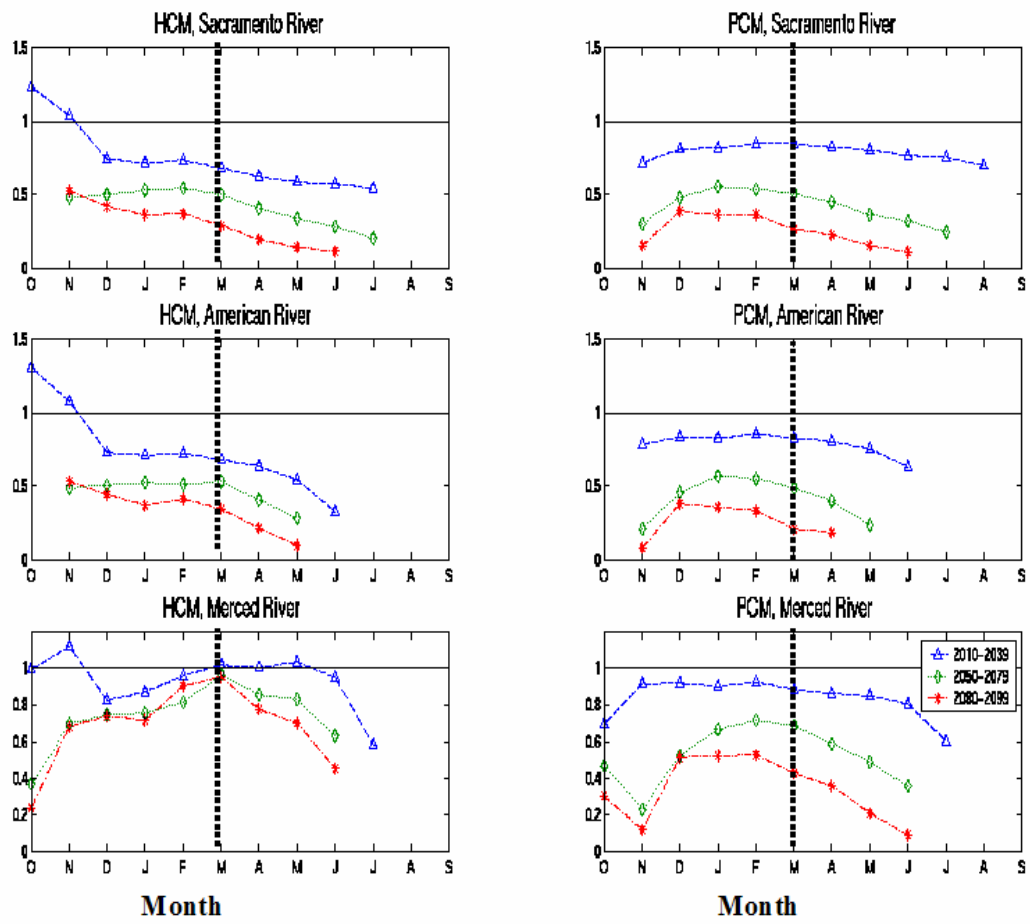

Fig. 9 The ratio of projected to present day total snow for each month based on the HadCM2 (left column) and the PCM (right column) for the Sacramento River, American River, and Merced River, for present day (light blue, validation), 2010-2039 (dark blue, circle), 2050-2079 (green, triangle), and 2079-2099 (red, diamond). The vertical dashed line represents the end of season snow amount. 
Changes in the snowmelt timing coupled with increased winter-time warm precipitation (rain) suggest an increased likelihood of high streamflow days that may result in floods. To evaluate likelihoods of future flooding, 30 year high flow days were calculated and ranked for both the HadCM2 and PCM, as well as for the present day period. Fig. 10 indicates that for both the relatively warm, wet HadCM2 and cool, dry PCM, there is a significant increase in the likelihood of high flow days. For each curve shown in Fig. 10, the median of the annual maximum daily flow $(50 \%)$ increases with increasing temperature. The 5\% exceedance high flow (the rightmost symbols in each plot) for the projected climates exceeds current conditions, implying an increased likelihood of high flow days (i.e. floods).

\section{Flood Modeling}

The ability to forecast high flows sufficiently far in advance under present and future climate conditions can reduce the loss of property and life. One of the first successful 48-hour advance numerical weather and streamflow forecasts was performed in January 1995 (Miller and Kim 1996a) along the Russian River in Northern Coastal California (Fig. 11). During the first week of January 1995, there were three storm systems that made landfall in the Northern Coastal region closely spaced in time. After the second storm, the ground became saturated and forecasts indicated that flooding (500 CMS) would occur 42 hours after the forecast was made. This simulation was based on a three-step procedure. Our modeling system (Miller and Kim, 1997) automatically obtained, via file transfer protocol (FTP), a global forecast from the U.S. National Weather Service. The global forecast provided our regional scale numerical weather prediction model with the initial and lateral boundary conditions needed to generate a fine-scale forecast, which in turn provided input to our coupled hydrologic model.
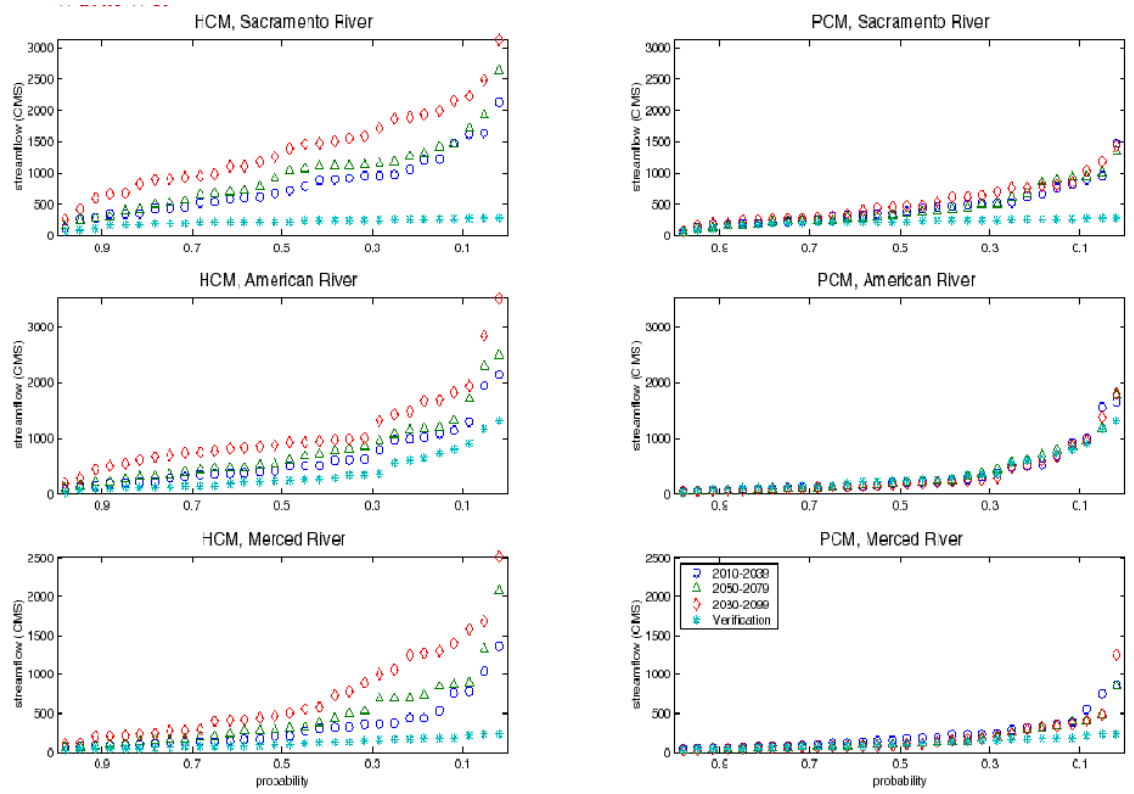

Fig. 10. Daily streamflow excedance probability based on the HadCM2 (left column) and the PCM (right column) for the Sacramento River, American River, and Merced River, for present day (light blue, validation), 2010-2039 (dark blue, circle), 2050-2079 (green, triangle), and 20792099 (red, diamond). 
This initial work has since advanced with ensemble streamflow simulations and data assimilation. The U.S. National Weather Service-River Forecast Center has developed flash flood modeling techniques with increased forecast skill. There have been successful 72-hour streamflow forecasts when the weather system has good predictability. Now-casting has also emerged as an accurate approach for evaluating weather systems at very short time intervals based on weather radar and remote sensed data.

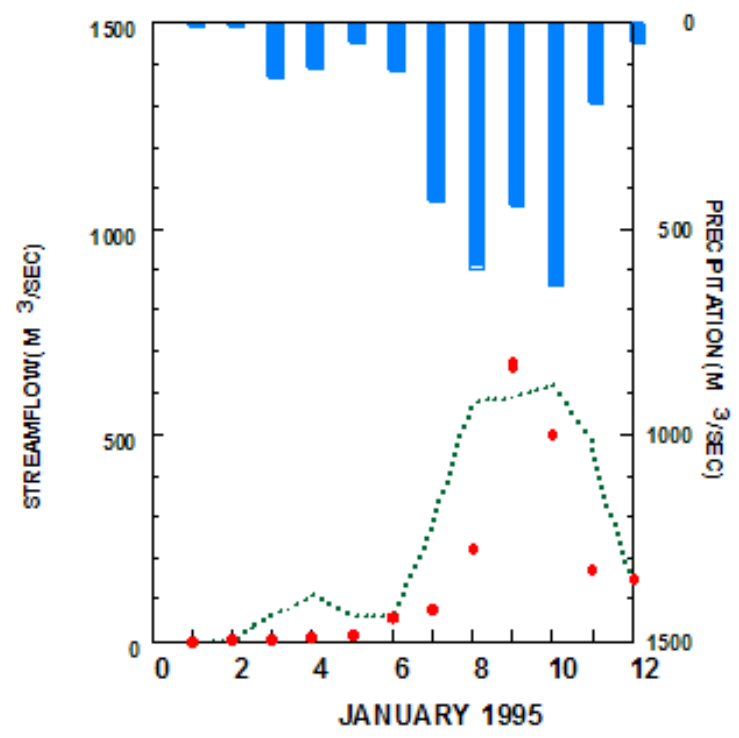

Fig. 9. One of the first 48-hour numerical weather-streamflow predictions was made for the first 12 days of January 1995. The green dashed line is the streamflow forecast, the red dots are stream gauge observations, and the blue bars are the precipitation forecast (Miller and Kim 1996).

During the last five years, the U.S. National Weather Service has been implementing the Advanced Hydrologic Prediction Services (AHPS). AHPS is a federally funded modernization initiative that allows for an incremental introduction of new products and services across the U.S.. The AHPS provide new forecast products depicting the magnitude and uncertainty of occurrence for hydrologic events from hours to days to weeks. The AHPS leverages data and systems from the U.S. National Weather Service and collaborators, including Lawrence Berkeley National Laboratory. It consists of radar data, river gage data, weather observations, snow cover/melt data, precipitation forecasts, climate predictions, reservoir releases, and satellite data.

\section{Summary and Conclusions}

There is strong evidence that the lower atmosphere has been warming at an unprecedented rate during the last 50 years, and it is expected to further increase at least for the next 100 years. Warmer air mass implies a higher capacity to hold water vapor and an increased likelihood of an acceleration of the global water cycle. This acceleration is not validated and considerable new research has gone into understanding aspects of the water cycle (e.g. Miller et al. 2003). Several significant findings on the hydrologic response to climate change can be reported. It is well understood that the observed and expected warming is related to sea level rise. In a recent seminar at Lawrence Berkeley National Laboratory, James Hansen (Director of the Institute for 
Space Studies, National Aeronautics and Space Administration) stressed that a $1.25 \mathrm{Wm}^{-2}$ increase in radiative forcing will lead to an increase in the near surface air temperature by $1^{\circ} \mathrm{C}$. This small increase in temperature from 2000 levels is enough to cause very significant impacts to coasts. Maury Roos (Chief Hydrologist, California Department of Water Resources) has shown that a $0.3 \mathrm{~m}$ rise in sea level shifts the San Francisco Bay 100-year storm surge flood event to a 10 -year event. Related coastal protection costs for California based on sea level rise are shown in Fig. 13 (Wilkinson et al. 2002).

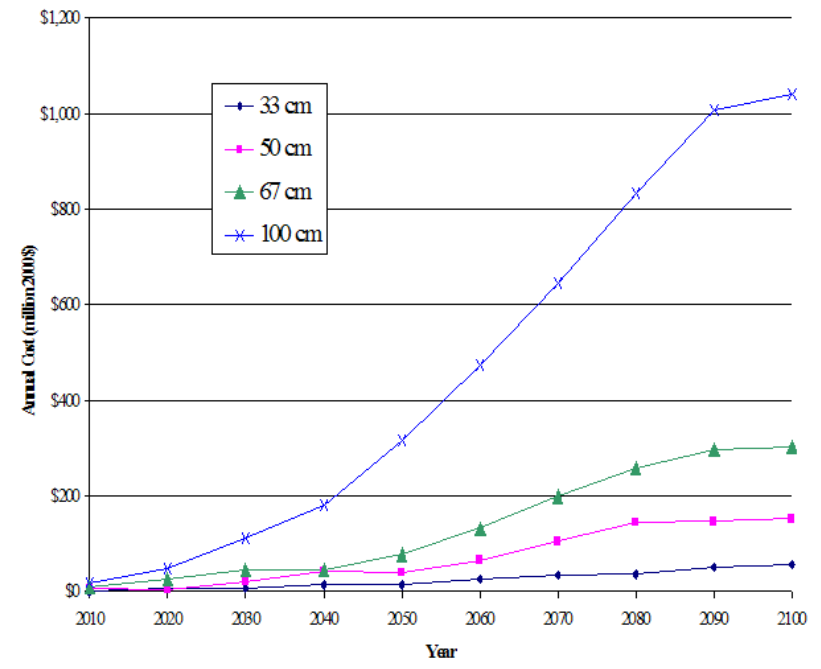

Fig. 13. California costs for coastal protection for sea level rise of $33 \mathrm{~cm}, 50 \mathrm{~cm}, 67 \mathrm{~cm}$, and $100 \mathrm{~cm}$.

In addition to rising sea level, snowmelt-related streamflow represents a particular problem in California. Model studies have indicated that there will be approximately a 50\% decrease in snow pack by 2100 . This potential deficit must be fully recognized and plans need to be put in place well in advance. In addition, the warmer atmosphere can hold more water vapor and result in more intense warm winter-time precipitation events that result in flooding. During anticipated high flow, reservoirs need to release water to maintain their structural integrity. California is at risk of water shortages, floods, and related ecosystem stresses.

More research needs to be done to further improve our ability to forecast weather events at longer time scales. Seasonal predictions have been statistical and only recently have studies begun to use ensemble simulations and historical observations to constrain such predictions. Understanding the mechanisms of large-scale atmospheric dynamics and its local impacts remain topics of intensive research.

The ability to predict extreme events and provide policy makers with this information, along with climate change and hydrologic response information, will help to guide planning to form a more resilient infrastructure in the future.

Acknowledgements: Support for this manuscript provided by the US Department of Energy Office of Science, Office of Biological and Environmental Research under contract DE-AC0376F00098. Climate change and hydrologic response research was supported by NASA Grant NS2791 and California Energy Commission. The early flood forecasting model development and 
simulations were supported through a US DOE Laboratory Directed Research and Development Grant. This manuscript is Lawrence Berkeley National Laboratory Report LBNL-54041.

\section{References}

Barnola, J.M., D. raymond, Y.S. Korotkevitch, and C. Lorius, 1987: Vostok ice core: A 160,000 year record of atmospheric $\mathrm{CO}_{2}$, Nature, 329, 408-414.

Burnash, R.J., R.L. Feral, and R.A. McQuire, 1973: A generalized streamflow simulation system. In: Conceptualization modeling for digital computers. U.S. National Weather Service.

Ingram, B. L., Ingle, J. C., and Conrad, M. E. (1996) Isotopic records of Pre-historic salinity and river inflow in San Francisco Bay Estuary, in San Francisco Bay: The Ecosystem (J. T. Hollibaugh, Ed.), Amer. Assoc. for the Advancement of Science, Pacific Division, San Francisco, CA, 35-61.

Intergovernmental Panel on Climate Change, 2001: Climate Change 2001: The Scientific Basis. Cambridge Univ. Press. 881pp.

Intergovernmental Panel on Climate Change, 1995: Climate Change 1995: The Science of Climate Change. Cambridge Univ. Press. 531pp.

Intergovernmental Panel on Climate Change, 1990: Climate Change: The IPCC Scientific Assessment. Cambridge Univ. Press. 362pp.

Jeton, A.E., M.D. Dettinger, and J.L. Smith, 1996: Potential effects of climate change on streamflow: Eastern and western slopes of the Sierra Nevada, California and Nevada. U.S. Geological Survey, Water Res. Investigations Rep. 95-4260, 44pp.

Keeling, C.D., R.B. Bacastow, A.F. Carter, S.C. Piper, T.P. Whorf, M. Heimann, W.G. Mook, and $\mathrm{H}$. Roeloffzen, 1989: A three dimensional model of atmospheric $\mathrm{CO}_{2}$ transport based on observed winds: 1. Analysis of observational data. In: Aspects of climate variability in the Pacific and Western Americas. Peterson (ed.), Geophysical Monograph, 55, AGU, 165-236.

Knowles, N. and Cayan, D. R., 2002. Potential effects of global warming on the Sacramento/San Joaquin watershed and the San Francisco estuary. Geophys. Research Letters, 29, 1891.

Lettenmaier, D.P. and T.Y. Gan, 1990: Hydrologic sensitivities of the Sacramento-San Joaquin River Basin, California, to global warming. Water Resources Res, 26, 69-86.

Miller, N.L. and J. Kim, 1996: Numerical prediction of precipitation and river flow over the Russian River watershed during the January 1995 California storms. Bulletin Amer. Meteorological Soc. 77, 101-105.

Miller, N.L. and J. Kim 1997: The Regional Climate System Model. In Mission Earth: Modeling and Simulation for a Sustainable Global System. Ed. M. Clymer and C. Mechoso, Soc. Comp. Sim. Inter., 55-60.

Miller, N.L., J. Kim, R.K. Hartman, and J. Farrara, 1999: Downscaled climate and streamflow study of the Southwestern United States. J. Amer. Water Resources Assoc, 35, 1525-1537.

Miller, N.L., K.E. Bashford, E. Strem, 2003: Potential impacts of climate change on California hydrology. J. American Water Resources Association, 39, 771-784.

Miller, N.L., A. A.W. King, M.L. Wesely and others, 2003:The U.S. Department of Energy Water Cycle Pilot Study. Bulletin of the American Meteorological Society, In Review.

Wigley, T.M.L. and S.B.C. and Raper, 2001: interpretation of high projections of global-mean warming. Science, 293, 451-454.

Wilby, R.L. and M.D. Dettinger, 2000: Streamflow changes in the Sierra Nevada, California, simulated using statistically downscaled general circulation model output. In: Linking Climate Change to Land Surface Change, Ed. McLaren and Kniven, Kluwer Academic Pub., 99-121.

Wilkinson, R. and others, 2002: Preparing for a climate change: California. Report of the California Regional Assessment Group, U.S. Global Change Research Program. 850pp. 